\title{
Exploitation and Management of Low Input Grassland Systems
}

\author{
Roxana VIDICAN ${ }^{1}$, Lucien CARLIER ${ }^{2}$, Ioan ROTAR ${ }^{1}$, Anamaria MĂLINAȘ ${ }^{*}$ \\ ${ }^{1}$ Faculty of Agriculture, University for Agricultural Sciences and Veterinary Medicine, \\ 3-5 Manastur Street, Cluj-Napoca, Romania \\ ${ }^{2}$ Institute for Agriculture and Fisheries Research, ILVO, Merelbeke, Belgium \\ *corresponding author: ciure_ana@yahoo.com
}

Bulletin UASVM series Agriculture 77(1) / 2020

Print ISSN 1843-5246; Electronic ISSN 1843-5386

DOI:10.15835/buasvmcn-agr: 2019.0031

\begin{abstract}
By this research the authors aimed to analyse the evolution and management of low-input grassland from a specific area in the Apuseni Mountains, in order to define what can be the result of a low input grassland system on the botanical composition of the grasslands and on the income of the farmers. In addition a full description of Flanders area with special attention to its grassland management is given, such that one can make a comparation between those two different cultures: the Province of East Flanders, Belgium and the area of Apuseni Mountains, Cluj County, Romania. Flanders (Belgium) and the area of Cluj County, Apuseni Mountains (Romania), are completely different not only in terms of their people with their own life-styles and culture, but also in terms of uses and management of arable land and grasslands.
\end{abstract}

Keywords: grassland, Flanders, Transylvania, management

\section{INTRODUCTION}

There is no official definition of "low input farming systems". The main definition explicitly addressing the concept has been proposed by Parr (1990): low input farming systems are those who "seek to optimize the management and use of internal production inputs (i.e. on-farm resources) and to minimize the use of production inputs (i.e. off-farm resources), such as purchased fertilizers and pesticides, wherever and whenever feasible and practicable, to lower production costs, to avoid pollution of surface and groundwater, to reduce pesticide residues in food, to reduce a farmer's overall risk, and to increase both short- and longterm farm profitability".

Low input farming systems should be analysed in a holistic vision: the idea of a farming system is thus essential to capture the complex relationships playing at the cropping system and the landscape ecology levels which enable the farmer to rely on low off-farm inputs. Fundamentally, the numerous nutrient flows between the different boxes of the farming systems entail the necessity of nutrients of natural origin at the farm level (Akeroyd and Page, 2011). Two main sources are considered: the $\mathrm{N}$-fixation by legumes in the crop rotation and, more generally, the existence of non cultivated (non ploughed) crops able to take the nutrients from the soil at a level which does not alter the sustainability of nutrients cycles. The set of such non cultivated crops (e.g. permanent grasslands, meadows, scrubs, hedges) sometimes labelled semi-natural vegetation in the field is forming what rural geographers calls the saltus (Poux, 2005; Willner et al., 2019).

The "saltus" is a concept found in French agrarian history and geography which refers to the use of uncultivated, non-forested communal 
land used for grazing agricultural livestock. The "saltus" (wilderness) thus stood in contrast to the "ager" (cultivated agricultural land) and the "silva" (forested land used for its wood resources). The idea of the saltus was however defined more on social terms (i.e. communal agricultural land) than on the basis of the type of vegetation on this land. On the basis of French agrarian histories, it appears that the use of the word "saltus" to describe this type of land use largely fell out of use after the 16th century. However the disappearance of the term "saltus" does not necessarily mean that this approach to land use also disappeared. On an agro-ecological level, the saltus may be seen as land in which plant growth and fertility is natural, in that external assistance is not required in order to support nutrient cycles. The permanent or semi-permanent nature of saltus vegetation is related to its functionality, with the fertility of the saltus and the entire agrosystem being supported by the natural fertilizers provided in animal wastes. On a socio-agrarian level, use of the saltus provides farmers with a means of adding value without incurring any costs other than for labour and livestock. Furthermore, current concerns regarding the relationships between agriculture and biodiversity would appear to support a revival of this idea. However the habitats that may be understood as making up the saltus are in decline in France and throughout Europe, due to the increasing use of cultivated agricultural land for animal feeding. While the vegetation of the saltus is sometimes described as "semi-natural", it is more accurate to describe it as natural but managed by man. This vegetation is often perceived as unproductive, but in fact can play important roles in agricultural production by providing feed sources and shelter for animals and also protecting land from erosion (Feurdean et al., 2018). The importance of the so-called seminatural vegetation of the saltus in maintaining biodiversity also cannot be underestimated. It is essential to note that the saltus is generally valued by grazing livestock, which ensure a fertility transfer through an appropriate use of manure on cultivated land (Melville et al., 2018). Thus, historically, autonomous low input farming systems in Europe have been set on the basis of mixed livestock-crops-saltus systems.

Worldwide pastoral rangelands are the primary and only resource on which both wild and domesticated herbivores depend. As the human population has increased, pastures has been converted into cropland, resulting in an overgrazing of the remaining grasslands (Carlier et al., 2009). The grassland area decreased in Western Europe with at least 8 million ha since the fifties of the last century. In the same period other traditional forage crops, like fodder beets and red clover almost disappeared, while the cultivation of the maize became more popular. Western European dairy farms are nowadays mostly based on the cultivation of two crops: grassland and maize.

\section{MATERIALS AND METHODS}

The study aimed to analyse the exploitation and management of low input grassland systems. The analyse focused on the Province of East Flanders, Belgium and a speciffic area of Apuseni Mountains, Cluj County, Romania. Several indicators were taken into account, such as the types of grasslands, the floristic composition, the management applied, the modern constraints for grassland management and the European Union grassland policy. This study was an exploratory study, meant to give an overview on the differences between the management of grassland and it's results as they are influenced by the two different cultures analysed.

\section{RESULTS AND DISCUSSIONS}

Grasslands in Transylvania. The mountain area is a geographical entity with a clear delineation in Romania. It stretches across 28 counties (out of $41)$, covering about $31 \%$ of the country $(23,54 \%$ of this surface being covered by agricultural land), 63 597 cities and communes, which have over 2890 villages with more than three million inhabitants (Balteanu et al., 2016).

Relief, essential component of the geographical landscape, presents the overall and regional features combination of Romania, an impressive harmony, which provided, in ancient times not only the local population ethno genesis favourable conditions, but over the centuries and helped maintain his being ethnic. The mountains are far from reaching the height of the Alps, therefore these mountains should be considered as medium in high, scaled in a European frame. Even in the highest of them, the Carpathians, only $25 \%$ of their scope exceeds $1500 \mathrm{~m}$ above sea level in the Eastern Carpathians only 5\% and less than 1\% in 
the Apuseni Mountains. Taking into account the wide ridge platforms, and generally gentle slopes of Romanian mountains, ceiling permanent settlements in many places rises above $1000 \mathrm{~m}$ altitude, and sometimes even over $1200 \mathrm{~m}$ in the Apuseni Mountains.

In Romania, as elsewhere across most of lowland Europe, grassland is not the natural climax vegetation, but with grassland probably always present, especially on steep, unstable or slumping marl slopes. Millennia of human management as meadows (still frequently mown by scythe) or pastures (grazed by cattle and sheep, with some water-buffalo and goats) have created plant and animal rich dry and mesic grasslands, derived from species of pre-existing treeless or semi-treeless habitats. These grasslands are outstanding both in extent and quality of plant species present, several of restricted Romanian or European distribution. They are also rich in arthropods (notably Lepidoptera), herpetofauna and birds.

The surface covered by our analyse is an impressive mixture of biodiversity, history, culture, and is located in the central part of the Apuseni Mountains. The Apuseni Mountains are inhabited by the "Moti", a people of Roman origin. Colonisation of the mountain began from the valleys. Until the 19 th century, the mountain was inhabited only during the summer months when the land was used as mountain pasture.
The people lived in small, one roomed "mutăturas" surrounded by stables (Figure 1).

An increasing population led to the foundation of permanent settlements around 1880. The houses were enlarged to two and three roomed buildings and some were even bigger (Goia et al., 2008). The actual state of species and landscape diversity is remarkable high in the whole area of the Apuseni Mountains and results from traditional and extensive management practices (a management with low-input). Altogether 9 Natura 2000 grassland habitats occur in the Apuseni Nature Park.

The mosaic of floristically different grassland types is the product of slope gradients and associated characteristics (Figure 2), mainly water storage capacity, that in turn are related to soil depth, and management factors, including grazing intensity, hay yield and fertilization. In which concerns the grassland management, each year, from May to July, most of the cattle and sheep are brought to the high mountain pastures, eg. The common "Poiana Călineasa", high pasture (ca. $9.000 \mathrm{ha}, 1.450 \mathrm{~m}$ ), consisting of grassland and forest. The area is unfertilized and heavily grazed at a density of 0.64 livestock cows ha-1 (including the forest) and 1.05 livestock units/ha grassland.

During either the winter or spring the meadows are fertilized with farmyard manure, which is transported by horse drawn wagons, deposited in heaps and spread manually. Approximately 90 $\mathrm{t} \mathrm{ha} \mathrm{a}^{-1}$ fermented manure is spread on the mead-

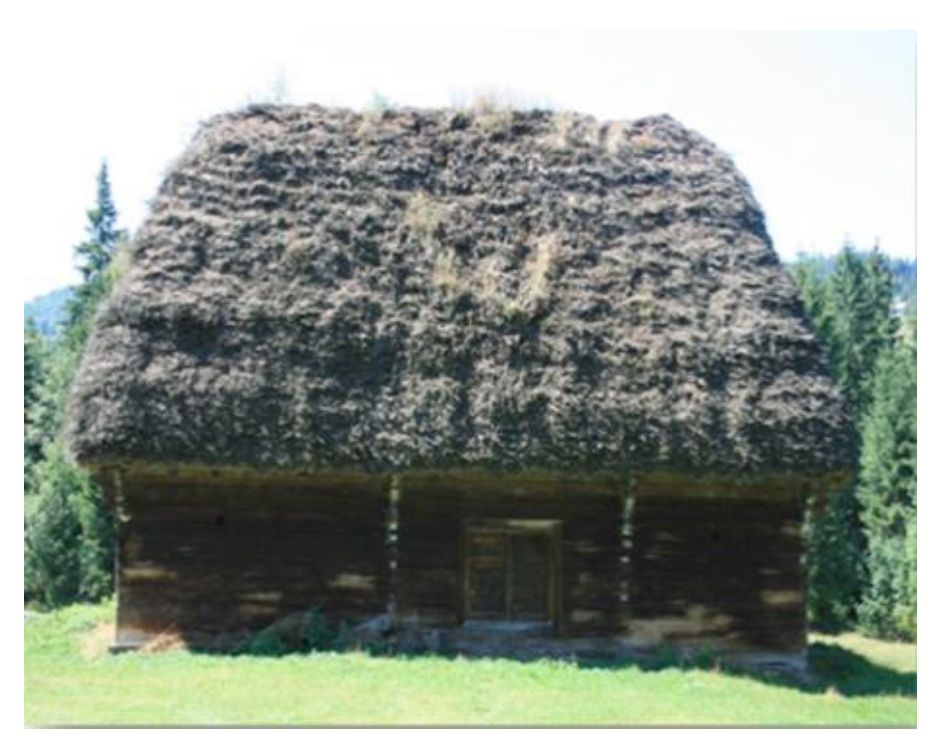

Figure 1. Shed covered with spruce branches in Apuseni Mountains (Original) 


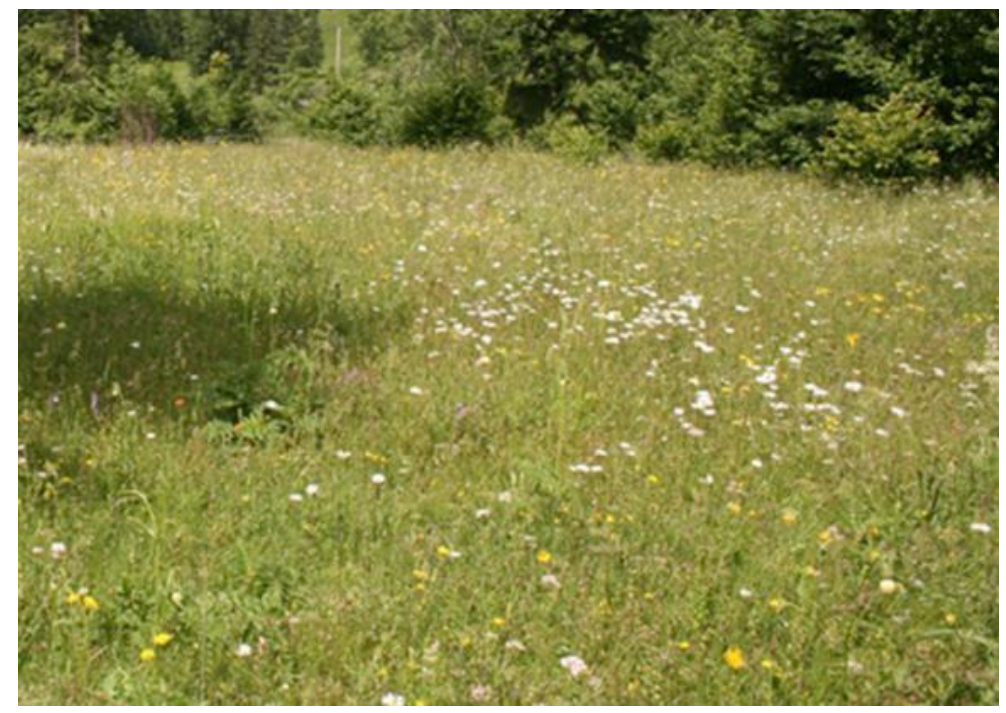

Figure 2. Grassland with multi-colourfull appearance in Apuseni Mountains (Original)

ows which were cut twice, and ca. $20 \mathrm{t} \mathrm{ha}^{-1}$ on the meadows cut once.

The basic needs of the people are provided by a subsistent production and animal husbandry. It is for this reason that hay production plays an important role, as forage is vital for livestock maintenance during the long winter period. The work carried out consists of many different activities around gardening, agriculture, forest use, craftwork and trade. The specific performance of each activity shapes the species composition and structure of the habitats, and the landscape as a whole. The human activities and the landscape are functionally connected to the adjacent areas, ranging from administrative centres of the community in the valley to high summer pastures in the mountains. Each household owns approximately 3 hectares of farmland. This consists mostly of meadows, together with a small garden and small fields where people cultivate potatoes and occasionally cereals, such as rye, barley and oats. Most of the gardens are fenced to keep grazing animals out. The households have a few (1 to 3 ) cattle originating from a mixture of different races, sheep's (3 to 5) and pigs. Each member of a family has an established activity: the woman guards the animals and manages the cheese production; meanwhile the men harvest the timber from the forest.

In the Apuseni Mountains farmers take care of the medical plant Arnica (Arnica montana) and manage these specific meadows and harvest it for homeopathic remedies: Arnica flowers have been used for reducing the swelling and pain of bruises, sprains, muscle/joint problems and insect bites.

The socio-economic landscape suffered importantly of the changes defined by an important economic and social increase, drawn by the differences in family structures, equipment and capital. The driving forces of these changes were the availability of new technology (electricity, chainsaw), new economic pressures and changes, corruption and less control over private activities. In particular, the elderly remain bound to their traditional ways of life and find themselves in increasing poverty. The population is declining in the face of limited employment opportunities and poor services. Due to its specific cultural landscape these area presents a good prospect in agro tourism activities.

Species-rich meadows on the driest and steepest, south- or south-west-facing slopes, hillocks or terraces are dominated by fescues, feather-grasses and have extensive patches of Carex. Another grassland type, a more species-poor Agrostis-Festuca community on moister and less lime-rich soils is generally managed as pasture and often associated with grazed oak plateau wood-pasture, a cultural and ecological feature of the Saxon Villages. This grassland grades into moderately moist and more nutrient-rich, neutral to mildly acid pastures and meadows. Around the villages, some rare examples survive of mesic semi-natural, speciesrich hay-meadows, although most of these have 
apparently been replaced by 3- to 4-year leys of fodder legumes. In damp, nutrient-rich grasslands the plant communities sometimes include more mountainous species such as Narcissus poeticus, Persicaria bistorta, Succisa pratensis, Trollius europaeus and Veratrum album. Around 20 species are mentioned in the "red list" of near threatened or vulnerable plants, like some Orchis species (Orchis militartis/ustulata).

Romanian botanists have described the characteristic grassland communities of Transylvania and have shown that these species-rich grasslands fall phytosociologically within communities of dry, more or less steppic grassland ('Dacio-Pannonic meadow-steppe'), in the orders Brometalia erecti, Festucetalia and Stipo pulcherrimae-Festucetalia pallentis. Although they are floristic outliers of the extensive Eurasian steppe vegetation, which extends to southern Romania (Banat and Danube Corridor) and the Pannonic steppe of Hungary, in Transylvania it is incorrect to term this vegetation steppe, for it is closer to the seminatural or secondary 'meadow-steppe' of Central Europe. These grasslands differ from true steppe by the presence of shrub communities, some relict woodland species and a substantial Mediterranean-Atlantic and Mediterranean floristic component, including orchids and bulbous (Liliaceae sensu lato) species.

Grassland in Flanders. Flanders is a part of Belgium with around 6 million inhabitants. The Leie, Dender and Schelde are the most important rivers. The soils are sandy to sandy loam with rather low organic C content. Only a small part is loam to clay in the so called Polders. The climate is mild (see climate, gulf stream and North sea) with winter averages around $0^{\circ} \mathrm{C}$ and summer averages around $22^{\circ} \mathrm{C}$. Rainfall is around $750 \mathrm{~mm}$ per year, most in spring and in autumn. The Province is situated near the North Sea and only small hills (120 $\mathrm{m}$ above sea level) show some tops on the flat land. Flemish agriculture is rather small but very intensive. There were in 201723.000 farms with an average area of 26 ha; 218.000 ha of temporary grassland, 140.000 ha permanent grassland, 120.000 ha of fodder maize, and 200.000 ha for other culture land. Some 1.200 .000 cattle, 115.000 sheep and 9.000 goats are hold. It is interesting to underline that in $70 \%$ (30 million) of the world wide azalea production comes from this province (250 ha green houses for horticulture), the azaleas grown in the region of Ghent are recognized as regional product (protected regional indication) and may show the EU label.

Flanders is an attractive living area for a lot of goose species. In the second half of the 19th century, goose in Flanders knew a great growth. Since 2000 the average number of goose coming to Flanders to overwinter in grasslands is quite stable: around 120.000 goose remain from November till February in the West Flemish polders and in some regions of East Flanders where they consume/ damage winter cereals and grasslands.

The winter goose are the Greater Whitefronted Goose (Anser albifrons, around 30.000

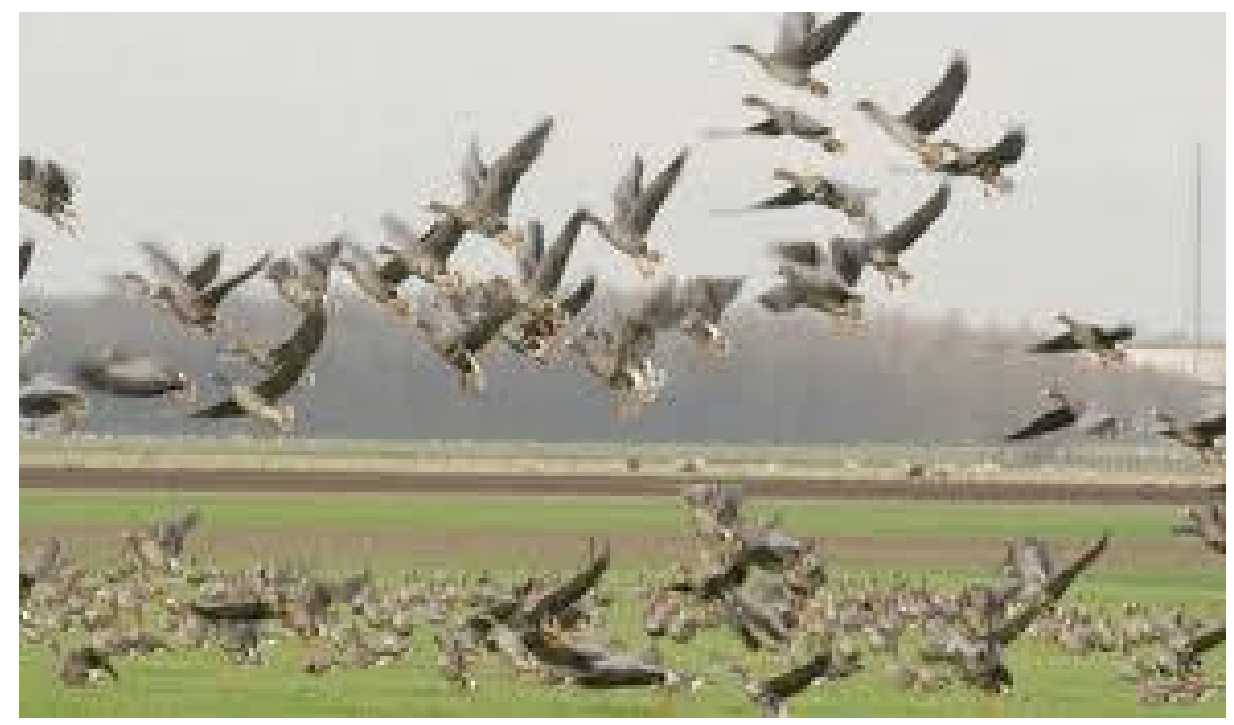

Figure 3. Goose species in Flanders ( Original) 
originating from Siberia), the Pink-footed Goose (Anser brachyrhynchus, some 45.000 from Spitsbergen - Norway) and the Greylag Goose (Anser anser, around 40.000 Scandinavian winter guests).

Not far away from Ghent, between the villages Kalken, Uitbergen, Schellebelle and Wetteren a wide nature area is situated along the river Schelde. It is a silence area of 950 ha wet grassland known as the "Kalkense meersen". The "Gentbrugse meersen" situated south of Ghent also along the Schelde (Figure 4). These are specific areas for birds and small animals and is part of the EU Birds Directive 79/409/EEG.

According to the EU Council Directive of 12 December 1991 concerning the protection of waters against pollution caused by nitrates from agricultural sources $(91 / 676 / \mathrm{EEC})$, groundwater may contain no more than $50 \mathrm{mg} / \mathrm{l}$ nitrates. The measures will ensure that, for each farm or livestock unit, the amount of livestock manure applied to the land each year, including by the animals themselves, shall not exceed a specified amount per hectare. The specified amount per hectare is the amount of manure containing 170 $\mathrm{kg} \mathrm{N}$. This is the equivalent of the slurry produced by 2 cows $\mathrm{y}^{-1} \mathrm{ha}^{-1}$.

The Flemish Government is responsible for the implementation of this Directive and tried to organize different Slurry Action Plans (Mestactieplan). At the beginning of 2011 the Flemish Government came to an agreement with the EU Commission by presenting its 4 th action plan. On the 6th of May 2011 the Flemish Parliament agreed on that Slurry Action Plan, which was published in the Belgian State Gazette on the 13th of May 2011 (Decree regarding the repealing of the Slurry Decree of the 22th December 2006). For the nitrogen fertilization norms are as follows for the period 2011-2014 are $350 \mathrm{~kg} \mathrm{ha}^{-1}$ for grazing + cutting and $370 \mathrm{~kg} \mathrm{ha}^{-1}$ for only cut grass. The limitation that only the equivalent of $170 \mathrm{~kg} \mathrm{~N}$ in manure per hectare may be applied, the amount of mineral $\mathrm{N}$ per ha on grassland is restricted to $200 \mathrm{~kg} \mathrm{ha}^{-1}$, which means that only $70 \%$ of the potential dry matter production of grassland can be reached. It leads also automatically to a more complex botanical composition with ore species, because the dominance of the $\mathrm{N}$-minded grass species becomes less important.

The most important grass species in natural and renovated grassland in Europe is perennial ryegrass (Lolium perenne L.). A lot of breeding work has been done on this species. Other important grass species, especially because of their production and/or quality characteristics are Italian ryegrass (Lolium multiflorum Lam.), tall fescue (Festuca arundinacea L.), meadow fescue (Festuca pratensis Hudson), cocksfoot (Dactylis glomerata L.), timothy (Phleum pratense L.), rough-stalked meadow grass (Poa trivialis L.), smooth-stalked meadow grass (Poa pratensis L.) and bent (Agrostis spp.) The development of new varieties, better adapted to biotic and abiotic stress situations (diseases, climate) and the application

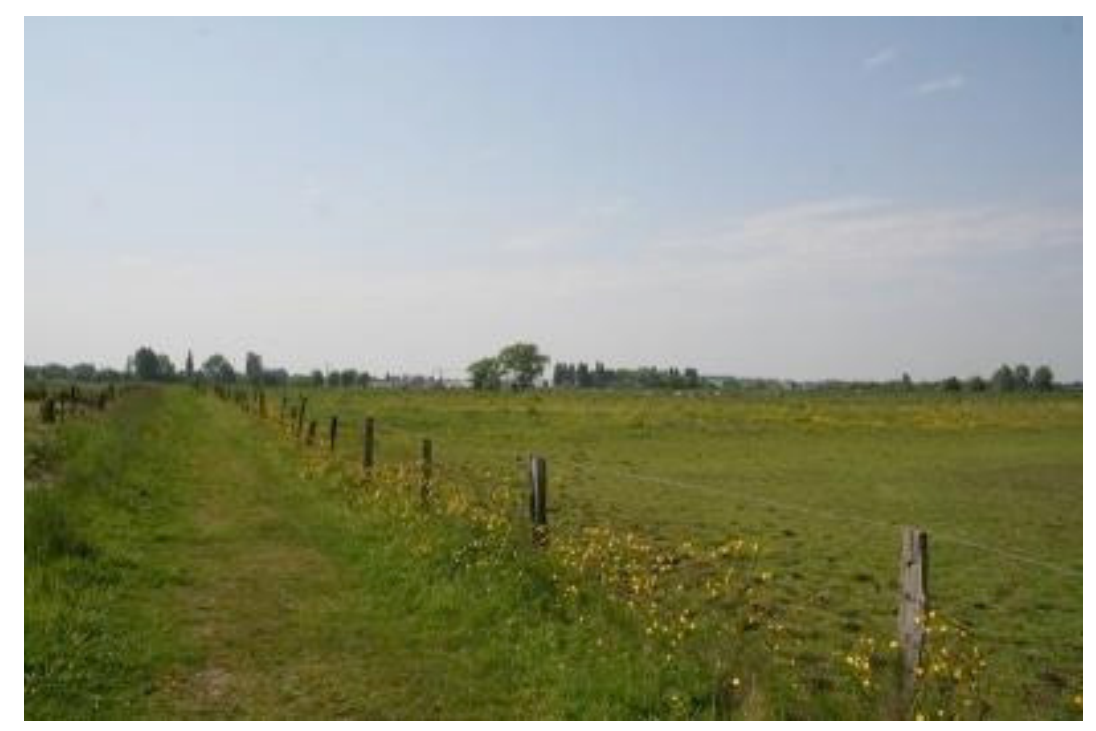

Figure 4. The Gentbrugse meersen (Original) 
of new technologies in pasture management with high fertiliser (nitrogen) input gave a substantially increased output in yield and quality (Balázs et al., 2017).

Grassland is mostly used for grazing and only part is used for pre wilted silage making. Grassland is based on perennial ryegrass and white clover with moderate nitrogen fertilization. Due to the Nitrate Directive it is in Flanders no more allowed to use more than $300 \mathrm{~kg} \mathrm{~N} \mathrm{ha}^{-1} \mathrm{y}^{-1}$ (organic and mineral together), which limits the yield capacity of perennial ryegrass. In the years 1960 to 1985 farmers could use unlimited quantities of nitrogen and some fertilized $600 \mathrm{~kg}$ mineral $\mathrm{N}$ per ha grassland. This exaggeration is no longer possible.

In summer time most cows graze (rotation or set stocking system) outside for at least some hours per day; only big farms ( $>100$ cows) prefer to keep the cows indoors (stable feeding) during the whole year, giving them cut grass, pre wilted grass silage and maize as forage, supplemented with concentrates.

Because of the new European Council Directive (CE) No 73/2009 (repealing Council Directive (CE) No 1782/2003 Flemish farmers tried to reduce their "permanent grassland" (EC definition), because they have in to keep their area "permanent grassland" equal and only when they sow the same are with a new grass/clover mixture for another 5 years, they may plough an old sward of the same area.

A lot of dicotyledonous (herbs/weeds) may take part in the botanical composition of grassland, although, they deliver a small part of the production, they may play a role in the mineral and vitamin repartition in the cow's diet. They never may take the lead position in good grasslands. If herbs dominate in grassland, they have to be controlled; grass species must always be the dominant part.

Because the inefficiency and the high costs, herbicides are only rarely used in grassland, in comparison to arable crops for the destruction of weeds. Therefore grassland is the environment friendly crop; only at the moment of renovation the old sward is killed with herbicides.

The last decades environment became more and more also an issue for the EU and its Member States. As one of the results are "management agreements" between the (local) governments and farmers.
In its Regulation (EC) $1782 / 2003$, the European Council writes: "Since permanent pasture has a positive environmental effect, it is appropriate to adopt measures to encourage the maintenance of existing permanent pasture to avoid a massive conversion into arable land." Nevertheless in its Regulation (EC) No 796/2004 of 21 April 2004 (laying down detailed rules for the implementation of cross-compliance, modulation and the integrated administration and control system provided for in of Council Regulation (EC) No 1782/2003 establishing common rules for direct support schemes under the common agricultural policy and establishing certain support schemes for farmers), the Commission defines: 'Permanent pasture': shall mean land used to grow grasses or other herbaceous forage naturally (self-seeded) or through cultivation (sown) and that is not included in the crop rotation of the holding for five years or longer. It means that the farmer after 5 years grassland (so called here permanent) may plough and convert to arable land; although he must compensate it by sowing the area with grasses. This wrongly ascribes the same value to intensive 6-years old sown grassland as to ancient pastures never ploughed in human memory. Some Member States, such as the UK, call sown grasslands permanent even in the year of reseeding as long as they go straight from grass back to grass. Thus current definitions prevent adequate targeting of support on the truly valuable grasslands, while possibly putting too many pointless controls on more intensive farmers. Internationally, grassland specialists define grassland "permanent" if its older than 10 years (Reheul et al., 2007).

In its policy of 2009, the European Council, highlights that Member States shall ensure that all agricultural land, especially land which is no longer used for production purposes is maintained in good agricultural and environmental condition. Member States shall define, at national or regional level, minimum requirements for good agricultural and environmental condition. They have to take into account the specific characteristics of the area concerned, including soil and climatic condition, existing farming systems, land use, crop rotation, farming practices, and farm structures.

Although, by analysing this Directive, it is clear that the mentioned standards (soil erosion, soil organic matter, soil structure, minimum level of maintenance and protection and management of 
water) may be defined and interpreted differently in the Member States. This may result in different standards for the same issue, even different standards leading to an unbalanced concurrence between the farmers in the different Member States.

\section{CONCLUSION}

The study highlighted that Flanders (Belgium) and the area of Apuseni Mountains (Romania) are completely different not only in terms of their people with their own life-styles and culture, but also in terms of uses and management of arable land and grasslands. Low-input meadows are an important part of the Romanian vegetation, including significant areas of pastures and meadows (about $11 \%$ of the country). They are the result of centuries of traditional exploitation by local farmers. From the analyses on organic farming in Romania, it was concluded that Romania has a great opportunity to make profit from this type of farming in an enlarged EU. Under these circumstances, grassland management techniques in this region should be developed efficiently, in order to preserve the grassland and vegetation types of high natural value. Natural grasslands in Flanders are not the most important issue for farm production, but must be kept like the evaluate in natural circumstances for the maintenance of the traditions and environment.

Acknowledgments. This work was supported by the Province of East Flanders.

\section{REFERENCES}

1. Akeroyd JR., Page JN (2011). Conservation of high nature value (hnv) grassland in a farmed landscape in Transylvania, Romania. Contribuţii Botanice XLVI: 57-71.

2. Balázs D, Wagner Viktoria, Csecserits Anikó, Becker T (2017). Vegetation and conservation of Central-European grasslands - Editorial to the 12th EDGG Special Feature. Tuexenia (37): 375-378.

3. Balteanu D, Dumitrascu Monica, Geacu S, Mitrica Bianca, Sima Mihaela (2016). Romania. Natura si Societate. (2nd ed.). Academia Romana.

4. Carlier L, Rotar I, Vlahova Mariana, Vidican Roxana (2009). Importance and functions of grasslands. Not. Bot. Hort. Agrobot. Cluj 37 (1): 25-30.

5. Feurdean A, Ruprecht E, Molnár Z, Hutchinson SM, Hickler T (2018). Biodiversity-rich European grasslands: ancient, forgotten ecosystems. Biological Conservation, 228: 224232.

6. Melville Bethany, Lucieer A, Aryal J (2018). Assessing the impact of spectral resolution on classification of lowland native grassland communities based on field spectroscopy in Tasmania, Australia. Remote Sens., 10(2): 308.

7. Parr JF (1990). Sustainable Agriculture in the United States. In Clive A. Edwards et al., Sustainable Agricultural Systems. Ankeny IA: Soil and Water Conservation Society.

8. Poux X., Narcy JB, Ramain B (2009). The "saltus": a historical concept for a better understanding the relationships between agriculture and biodiversity today. Courrier de l'Environnement de l'INRA, 57: 23-34.

9. Reheul D, De Vliegher A, Bommelé Livia, Carlier L (2007). The comparison between temporary and permanent grassland. Grassl. Sci in Europe, 12: 1-13.

10. Willner W, Roleček J, Korolyuk A, Dengler J, Chytrý M, Janišová M, Lengyel A, Aćić S, Becker T, Ćuk M, Demina O, Jandt U, Kącki Z, Kuzemko A, Kropf M, Lebedeva M, Semenishchenkov Y, Šilc U, Stančić Z, Staudinger M, Vassilev K, Yamalov S (2019). Formalized classification of semi-dry grasslands in central and eastern Europe. Preslia, 91: 25-49. 